\title{
Fracture Properties of Geopolymer Concrete Based on Metakaolin, Fly Ash and Rice Rusk Ash
}

Eliane Fernandes Côrtes Pires ${ }^{a}$, Claúdio Mesquita Campinho de Azevedo ${ }^{a}$, André Rocha Pimentab, Felipe José da Silva ${ }^{a, b} *$, Fathi Aref Ibrahim Darwish ${ }^{a}$

\author{
${ }^{a}$ Departamento de Engenharia Civil, Universidade Federal Fluminense, Niterói, RJ, Brasil \\ ${ }^{b}$ Curso Técnico em Mecânica Industrial, Instituto Federal do Rio de Janeiro, Paracambi, RJ, Brasil
}

Received: November 12, 2016; Revised: October 06, 2017; Accepted: October 11, 2017

\begin{abstract}
Geopolymers are exclusively mineral nature and are considered an alternative to materials based on Portland clinker, whose production accounts for about $5 \%$ of anthropogenic $\mathrm{CO}_{2}$ emissions in the world. The geopolymer cement concrete (GCC) may be prepared from natural oxide-aluminosilicates such as metakaolin (MK), or synthetic, such as fly ash (FA) together with active silica contained in the rice husk ash (RHA). The fracture properties of the Portland cement concrete (PCC) with $25 \mathrm{MPa}$ and $50 \mathrm{MPa}$, and of three different geopolymeric concretes with the same strength Classes were determined for comparative analysis. The aim of this study is to provide support to begin the use of geopolymers in the reinforced concrete precasting Industry. Three-point bending tests of notched beams with $a / \mathrm{d}$ (notch depth/beam depth) of 0.5 from RILEM TC80-FMT Recommendations were used to determine the critical values of $\mathrm{K}, \mathrm{G}, \mathrm{R}$ and J-integral for crack propagation under mode I. The results showed that the geopolymeric concretes exhibit similar mechanical behavior and fracture properties higher that those determined in PCC for the same strength class.
\end{abstract}

Keywords: geopolymer, concrete, fracture toughness, fly ash, rice husk ash.

\section{Introduction}

The geopolymers are considered ceramic materials. The ionic-covalent nature of their molecular bonds, the extent of the chains and the structural arrangement they form lead to particular properties in the fresh and hardened states ${ }^{1,2,3}$. Although the geopolymer slurry shows less autogenous retraction than Portland cement paste, during geopolymerization the reaction medium requires water as the ionic conduction vehicle $^{4}$. This water is essential to maintain the degree of saturation necessary for the geopolymerization to reach the required degree ${ }^{5,6}$. Excess water, as well as scarcity in the mixture, causes disequilibrium in the reaction and leads to unstable structure or with numerous physical discontinuities ${ }^{7}$. Despite the control, in practice it is extremely difficult to prevent discontinuities to be formed during geopolymerization since residual elastic tensions tend to be alleviated with the formation of discontinuities, often with the creation of microcracks ${ }^{8}$.

The mechanical behavior of mortars and geopolymer concrete revealed that they are like rocks and concretes of Portland cement, that is, they are classified as "quasi-brittle". This category refers to the fact that they present the elasticplastic localized deformation phenomenon in the region immediately ahead and around the end (tip) of preexisting discontinuities when submitted to mechanical stresses. In the case of discontinuities of acute elliptic geometry, as

*e-mail: felipe.silva@ifrj.edu.br occurs with cracks, the stress concentration makes it easy to reach the limit of tensile strength of the material leading to rupture, sometimes catastrophic ${ }^{9}$

The so-called Linear Elastic Fracture Mechanics (LEFM) and its derivation for the Nonlinear Fracture Mechanics (NLFM) are sciences that study the influence of the presence of these sharp discontinuities inside the material under mechanical loading. Different models have emerged over the last three decades to quantify the fracture toughness of quasi-brittle materials by considering the effects of the region of localized elastoplastic deformation (Fracture Process Zone, FPZ). However, most models require the separation of elastic and plastic components of the FPZ, which could only occur in controlled situations of successive loading and unloading in a piece of suitable geometry sensitized by a notch in a certain section, more loaded.

The 3-point bending test with concentrated load in the middle of the span became a standard test for quasi-brittle materials, whereas, for metals, the compact tensile test remained the most used. The pioneering works of Hillerborg ${ }^{10}$, Jenq \& Shah ${ }^{11}$ and Bazant \& Kazemi ${ }^{12}$ provided as early as the 90 s technical recommendations by RILEM ${ }^{13}$. The test model proposed by RILEM Technical Committee 80 Fracture Mechanics Tests (TC-80 FMT) became a reference standard, as an alternative to ASTM C 1018, which defined the tougness indixes under simple bending of non-notched beams with applied load in the center of the span. The main criticism associated with this model is due to the fact it is based 
on readings of maximum deflections at critical moments, such as the formation of the 1 st crack which is difficult to determine. As there is no macroscopic stress concentrator to aid in the localized formation of the FPZ, the crack can form in any position near the loaded section, which compromises the characterization by preventing any correlation between the size of the defect and the load applied in the material ${ }^{9}$.

Some fracture parameters such as the elastic energy release rate, $(\mathrm{G})$, stress intensity factor $(\mathrm{K})$, J-integral, fracture resistance ${ }^{\circledR}$ were adopted to characterize concretes of Portland cement and geopolymer.

The fracture toughness was used as a measure of the resistance of the material to the crack propagation ${ }^{14}$. The stress intensity factor was proposed in 1957 by Irwin to describe the intensity of the elastic behavior of the crack tip and symbolizes the linear elastic fracture mechanics. These parameters are presented below, but only for definition. More details could be obtained from LEFM Compendiums ${ }^{15-17}$.

The critical stress intensity factor in the mode I of crack opening, called $\mathrm{K}_{\mathrm{Ic}}$, is determined when $a=a_{\mathrm{c}}$, by ${ }^{18}$ :

$$
\% m / m C u=\frac{m_{C u}}{m_{C u}+m_{S n}} \times 100 \%
$$

where $\mathrm{P}$ is the active load, $a$ is the notch extension and equal to $50 \mathrm{~mm}, \mathrm{~b}$ is the width of the small beam and equal to $100 \mathrm{~mm}, \mathrm{~d}$ is the height of the notch equal to $100 \mathrm{~mm}$, $F_{3}(a / d)$ is a function given by:

$$
\% m / m S n=\frac{m_{S n}}{m_{C u}+m_{S n}} \times 100 \%
$$

The critical rate of strain energy release for propagation of a crack extension unit was obtained by:

$$
d_{p}=\frac{k \lambda}{\beta \cos \theta} s
$$

where $\mathrm{K}_{\mathrm{Ic}}$ is the stress intensity factor in the critical state and $\mathrm{E}$ is the modulus of elasticity calculated by the following ${ }^{13}$ :

$$
\mathrm{C}_{\mathrm{DCE}}=(\mathrm{CPE})^{\frac{1}{N}} \times \mathrm{R}_{\mathrm{tc}}^{\left(\frac{1}{\mathrm{~N}}-1\right)}
$$

where $\mathrm{S}$ is the span, equal to $400 \mathrm{~mm}$, $\mathrm{d}$ is the height of the beam, equal to $100 \mathrm{~mm}$ and $\mathrm{b}$ is the width of the beam, equal to $100 \mathrm{~mm}$. The parameter $\mathrm{V}_{1}\left(\alpha_{0}\right)$ was calculated from the following equation ${ }^{13}$ :

$$
V_{1}\left(\alpha_{0}\right)=0,76-2,28 \alpha_{0}+3,876 \alpha_{0}^{2}-2,04 \alpha_{0}^{3}+\frac{0,66}{\left(1-\alpha_{0}\right)^{2}}
$$

where: $\alpha_{0}=\frac{a_{0}}{d}=\frac{50}{100}=0.5$

The initial compliance, or initial flexibility, was calculated by the following:

$$
C_{i}=\frac{C M O D_{i}}{P_{I}}
$$

where the $\mathrm{CMOD}_{\mathrm{i}}$ is provided by the clip gauge, in a load acting on the elastic phase, $\mathrm{P}_{i}$.

R-curve studies stable crack growth and response to the effects of increased toughness.

Obtaining curves $\mathrm{R}_{\mathrm{I}}$ (resistance to fracture) was proposed by Ouyang \& Shah $^{19}$ from $\mathrm{K}_{\mathrm{Ic}}$ and $\mathrm{CTOD}_{\mathrm{c}}$ and expressed by:

$$
R=\beta \psi\left(a-a_{0}\right)^{d_{2}}
$$

where $a_{0}$ is the initial notch length of $50 \mathrm{~mm}$; The coefficients $\alpha$ (equation 8 ) and $\beta$ (equation 9) are determined from the biparametric model of fracture:

$$
\begin{gathered}
\alpha=\mu+\sqrt{\mu^{2}+1} \\
\beta=\frac{\left(K_{I c}\right)^{2}\left(d_{1} \alpha-\alpha+1\right)}{E \alpha\left(d_{1}-d_{2}\right)\left(\alpha a_{0 d}-a_{0}\right)^{d_{2}}}
\end{gathered}
$$

The coefficient $\mu$ is calculated as follows:

$$
\mu=\frac{\pi E^{2} f_{1}^{2} C T O D_{c}}{32 a_{0}\left(K_{I_{c}}\right)^{2} f_{2}^{2}}
$$

where $\mathrm{E}$ is the tangent modulus of elasticity, $f_{1}$ and $f_{2}$ are equal to 1.123 and 1.420 , respectively, tabulated for notched beam in the center of the span, under 3-point bending and with span/height ratio equal to 4 .

The roots of the equation, $\mathrm{d}_{1}$ and $\mathrm{d}_{2}$, are given by equation 11:

$$
d_{1}, d_{2}=\frac{1}{2}+\frac{\alpha-1}{\alpha} \pm\left[\frac{1}{4}+\frac{\alpha-1}{\alpha}-\left(\frac{\alpha-1}{\alpha}\right)^{2}\right]^{\frac{1}{2}}
$$

So,

$$
\begin{gathered}
\psi=1-\frac{d_{2} \alpha-\alpha+1}{d_{1} \alpha-\alpha+1}\left(\frac{\alpha a_{0}-a_{0}}{a-a_{0}}\right)^{d_{2}-d_{1}} \\
C T O D_{c}=\frac{6 P_{c} S a_{c} \sqrt{\left(1-\beta_{0}\right)^{2}+\left(1,081-1,149 \alpha_{c}\right)\left(\beta_{0}-B_{0}^{2}\right)}}{E d^{2} b} \\
\alpha_{c}=\frac{a_{c}}{d} \\
\beta_{0}=\frac{a_{0}}{a_{c}}
\end{gathered}
$$

The J-integral was proposed in 1968 by Rice ${ }^{16}$ to characterize the intensity of elastic-plastic behavior at the crack tip and symbolizes the mechanics of elastic-plastic fracture.

A J-integral can be determined according to the equation below:

$$
J=\frac{2 U}{b\left(d-a_{0}\right)}
$$

where $d$ represents the width of the specimen and $\left(\mathrm{d}-a_{0}\right)$ represents the height of the ligament, $a_{0}$ is the crack length 
equal to $50 \mathrm{~mm}, \mathrm{U}$ is the work performed during loading, calculated by integrating the area under the $\mathrm{P}-\delta$, (equation 17 ), where $\mathrm{P}$ is the instantaneous load and $\delta$ is the displacement of the point of application of the load.

$$
U=\int_{0}^{\delta} P d \delta
$$

The $\mathrm{J}_{\max }$ is obtained when $\mathrm{U}=\mathrm{U}_{\max }$, form $\mathrm{P}=\mathrm{P}_{\text {max }}$ and $\delta=\delta_{\max }{ }^{16}$.

This paper presents the fracture parameters of three types of geopolymer (GCC, GCC-20FA, GCC-20FA-RHA), obtained from different raw materials and compared with the results presented by Portland cement concrete (PCC) in two strength classes, $25 \mathrm{MPa}$ and $40 \mathrm{MPa}$, at 28 days of age.

\section{Materials and methods}

The fine aggregate was washed river sand with a fineness modulus of 2.66 and maximum dimension, $\mathrm{D}_{\text {máx }}$, of $24 \mathrm{~mm}$, considered as average size sand. The coarse aggregate used was of gneiss origin with a fineness modulus of $5.72 \mathrm{~mm}$, considered as level zero gravel with maximum size of $9.5 \mathrm{~mm}$.

The geopolymer cement used in the manufacturing of the geopolymer concrete beams was provided by Wincret Designer Concrete Products Ltda, based in São Paulo/SPBrazil. It is commercially called Cement Geo-Pol®, with $\mathrm{SiO}_{2} / \mathrm{Al}_{2} \mathrm{O}_{3}$ ratio equal to 5.35 and $\left(\mathrm{Na}_{2} \mathrm{O}+\mathrm{K}_{2} \mathrm{O}\right) / \mathrm{SiO}_{2}$ equal to 0.209 . The binder is usually supplied in two components, identified by the manufacturer as Component-A: pozzolanblend and Component B: alkali-polysilicate. For this work, Components A and B were provided separately from the fractions identified as Components A1: metakaolin, A2: unidentified solid-blend, B1: aqueous sodium silicate and B2: potassium hydroxide. The Portland cement used in the reference concrete was the CPIIF-32 manufactured by Lafarge/ Mauá S.A. and acquired in the local market. The mass ratio between the constituents of the concrete (of all matrices studied) was 1: 1.26: 0.99 (dry binder: sand: zero gravel) with water/dry binder ratio of 0.36 , setting characteristic resistance at 28 days of age, $f_{c k}$, of $40 \mathrm{MPa}$. Already for $\mathrm{f}_{\mathrm{ck}}$ $25 \mathrm{MPa}$, the mass ratio was 1: 2.00: 1.57 and factor water/ dry binder 0.46 , according to Table 1 .

The potassium hydroxide and sodium silicate solutions were prepared separately and mixed together at the time of molding. The aqueous silicate showed $\mathrm{SiO}_{2} / \mathrm{Na}_{2} \mathrm{O}$ ratio of 2.24. The potassium hydroxide solution had $8.7 \% \mathrm{~K}_{2} \mathrm{O}$. The metakaolin presented a $\mathrm{SiO}_{2} / \mathrm{Al}_{2} \mathrm{O}_{3}$ ratio of 1.60 , specific gravity of $2.52 \pm 0.32 \mathrm{~kg} / \mathrm{dm}^{3}$, specific surface of $1864.22 \mathrm{~m}^{2} / \mathrm{kg}$.

Fly ash (FA) was supplied by the company Pozofly S.A., based in the city of Porto Alegre/RS/Brazil. According to ASTM C618/12a it belongs to class F, of low pozolanicity. Its specific gravity was $2.32 \mathrm{~g} / \mathrm{cm}^{3}$ and the specific surface was $312.33 \mathrm{~m}^{2} / \mathrm{kg}$. Metakaolin was substituted in $20 \%$ volume with fly ash, originating the nomenclature of the GCC-20FA geopolymer matrix. Rice husk ash (RHA) was supplied by TecnoSil S.A., from the Rio Grande do Sul state and originated from biomass burning for steam and energy generation. Its specific gravity was $2.14 \mathrm{~kg} / \mathrm{dm}^{3}$, apparent density $890 \mathrm{~kg} / \mathrm{m}^{3}$, pozzolanic activity of $625 \mathrm{mg} \mathrm{CaO} / \mathrm{g}$. An alternative sodium silicate was made from RHA pre-solubilized to fully replace the commercial sodium silicate. In addition to using $20 \% \mathrm{FA}$, this alternative RHA sodium silicate was used resulting in the nomenclature of the GCC-20FA-RHA geopolymer matrix. To determine the fracture properties of plain concrete small beams, 24 notched beams were tested at three loading points, as recommended by RILEM $\mathrm{TC} 8-\mathrm{FMT}^{13}$. Three samples were formed for each matrix (PCC, GCC, GCC-20FA, GCC-20FA-RHA) by grouping each matrix with each strength class (25 and $40 \mathrm{MPa})$. All specimens were $500 \mathrm{~mm} \times 100 \mathrm{~mm} \times 100 \mathrm{~mm}$, with a span (S) / height (d) ratio of 4 , and a notch height $\left(a_{0}\right)$ and beam height $(\mathrm{d})$ ratio of 0.5 . The loading rate was $50 \pm 15 \mathrm{~N} / \mathrm{s}$. The deflection in the middle of the span was monitored through the resistive displacement transducer with electrical course $100 \mathrm{~mm}$, precision of $0.01 \mathrm{~mm}$, mark GEFRAN INC. The crack mouth opening displacement (CMOD) was monitored using clip-gage attached under the beam through the latex rods (Figure 1). All electrical sensors were read using the National Instruments Data Acquisition System Model cDAQ9217, assisted by the LabView 8.6 software.

\section{Results and discussions}

P-CMOD curves of both concrete strength class of 25 and $40 \mathrm{MPa}$ are shown in Figures 2 and 3, respectively. In class 25 , the geopolymer with the two ashes (GCC-20FARHA_25) showed the best results in stiffness, strength and critical value of CMOD.

Table 1. Concrete design parameters of classes 25 and $40 \mathrm{MPa}$.

\begin{tabular}{lcc}
\hline Parameters & Class 25 & Class 40 \\
\hline Compressive strength characteristic, $f_{c k}$ & $25 \mathrm{MPa}$ & $40 \mathrm{MPa}$ \\
Compressive strength of design, $\mathrm{f}_{\mathrm{cj}}$ & $35 \mathrm{MPa}$ & $49 \mathrm{MPa}$ \\
Standard deviation of design, $S_{d}$ & $5.5 \mathrm{MPa}$ & $5.5 \mathrm{MPa}$ \\
Water/Cement ratio, $w / c$ & 0.457 & 0.357 \\
Consumption of binder $/ \mathrm{m}^{3}$ of concrete & $459.52 \mathrm{~kg}$ & $640.75 \mathrm{~kg}$ \\
Proportion (by mass) & $1: 2.00: 1.57: 0.46$ & $1: 1.26: 0.99: 0.36$ \\
\hline
\end{tabular}




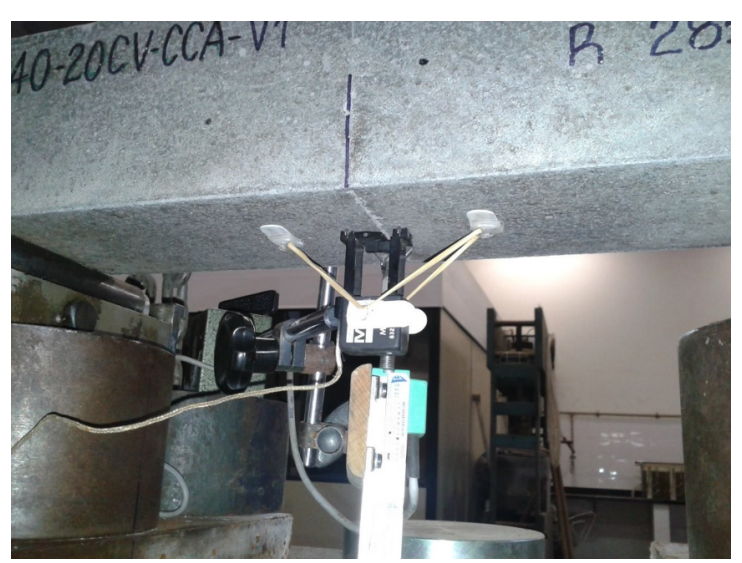

Figure 1. Clip Gauge placement detail for CMOD reading.

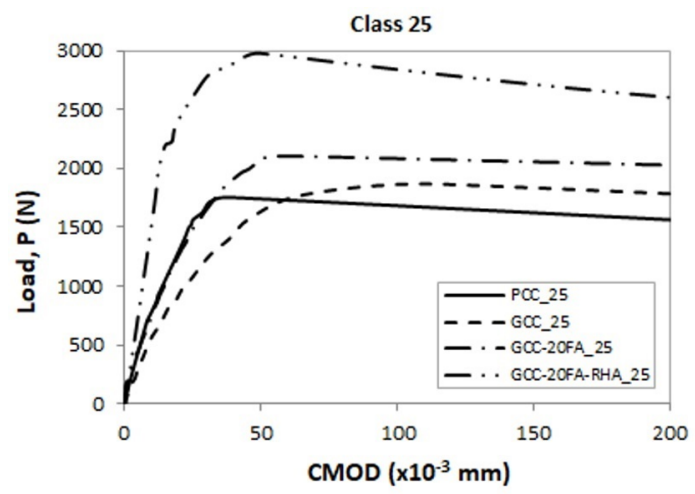

Figure 2. Variation of load with CMOD to $25 \mathrm{MPa}$ strength class of concrete for all matrices studied.

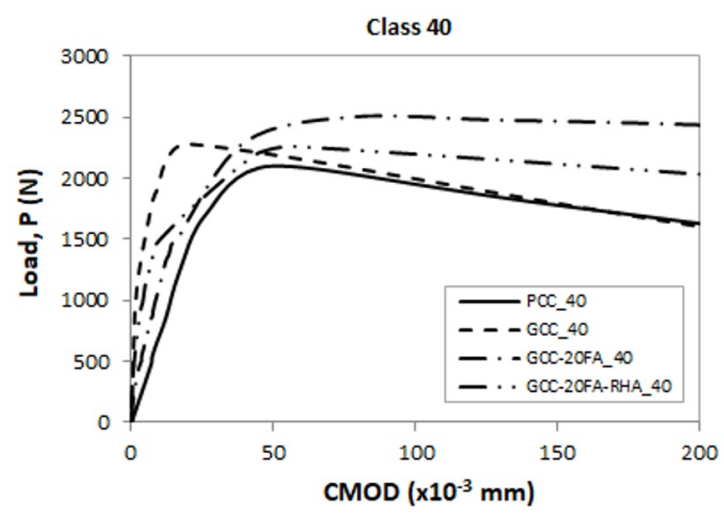

Figure 3. Variation of load with CMOD to $40 \mathrm{MPa}$ strength class of concrete for all matrices studied.

Although less rigid, the standard geopolymer (GCC_25) showed $\mathrm{P}_{\text {max }}$ and $\mathrm{CMOD}_{\mathrm{c}}$ higher than the PCC, indicative of higher toughness. With $20 \%$ of FA, stiffness was equivalent, but $\mathrm{P}_{\text {max }}$ was higher than that of PCC.

In class 40 , all geopolymers presented better results than PCC, with emphasis on GCC-20FA_40. In this class, the RHA silicate containing matrix did not repeat the superior performance as in class 25 . This could be attributed to the workability loss of the matrix with the lowest aggregate content even though there was an increase in $\mathrm{P}_{\text {max }}$.

Figure 4 shows $\mathrm{K}_{1}$ versus $\Delta a$ for notched beams of the strength class of $25 \mathrm{MPa}$ and the different matrices. The standard geopolymer had a small performance gain in relation to Portland, but the use of FA promoted a greater increase of the stress intensity factor, $\mathrm{K}_{\mathrm{r}}$. As for the influence of the RHA, the use of the sodium silicate of RHA provided a substantial improvement in $\mathrm{K}_{1}$ values of approximately $35 \%$ compared to the standard geopolymer.

A less selective behavior was observed in the beams of the class $40 \mathrm{MPa}$ (Figure 5).

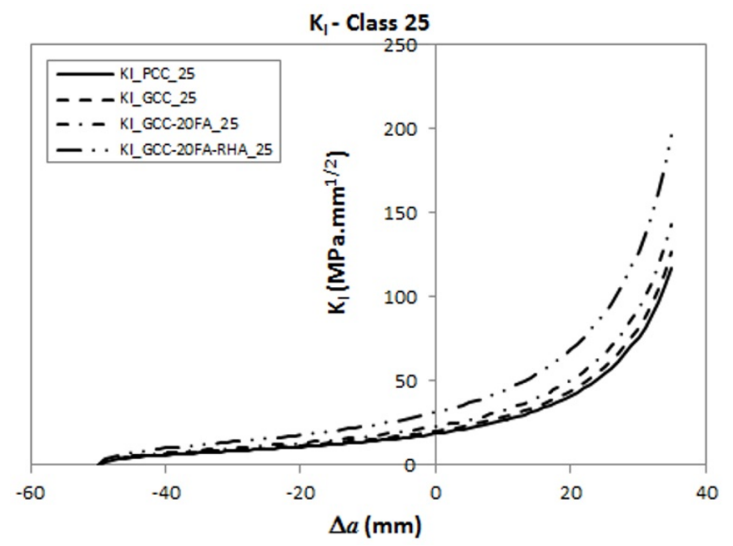

Figure 4. Variation of the stress intensity factor $\left(\mathrm{K}_{\mathrm{I}}\right)$ with the nominal extension of the crack $(\Delta a)$ for concrete notched beams of strength class of $25 \mathrm{MPa}$, with different matrices.

Although the $\mathrm{K}_{\mathrm{I}}$ curve of GCC-20FA-RHA_40 has remained above the others, it can be said that all presented

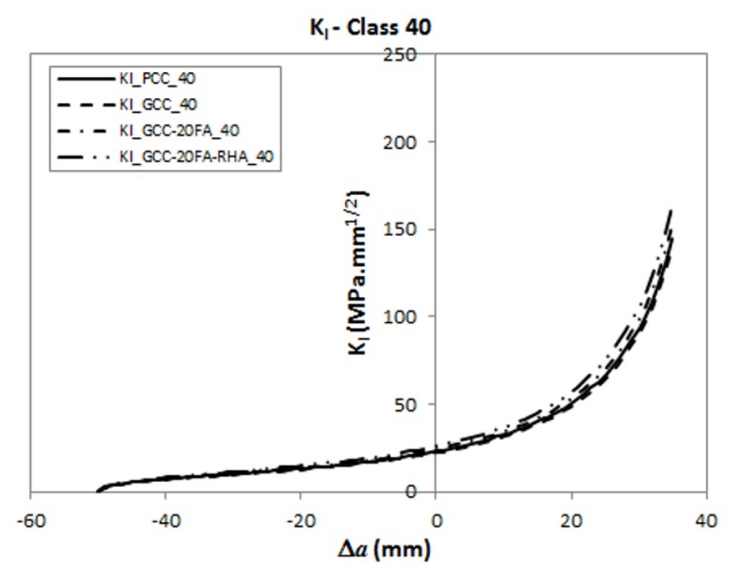

Figure 5. Variation of the stress intensity factor with the extension of the crack for concrete notched beams of strength class of $40 \mathrm{MPa}$, with different matrices.

similar performance. Another observation is that when compared to the $\mathrm{K}_{\mathrm{I}}$ curves of class 25 , there was no increase 
of toughness with the increase of strength class, except in GCC-20FA-RHA.

Figure 6 shows the $\mathrm{G}_{\mathrm{I}}$ values as a function of $\Delta a$ for beams of class $25 \mathrm{MPa}$, for the different concrete matrices. As can be seen, the GCC-20FA_25 had the best performance, surpassing the other geopolymers. The emphasis in relation to PCC_25 was almost $100 \%$. In terms of $\mathrm{G}_{\mathrm{I}}-\Delta a$, the standard geopolymer (GCC_25) and the geopolymer with the two ashes (GCC-20FA-RHA_25) presented similar performances, but both superior to PCC_25 by approximately $60 \%$.

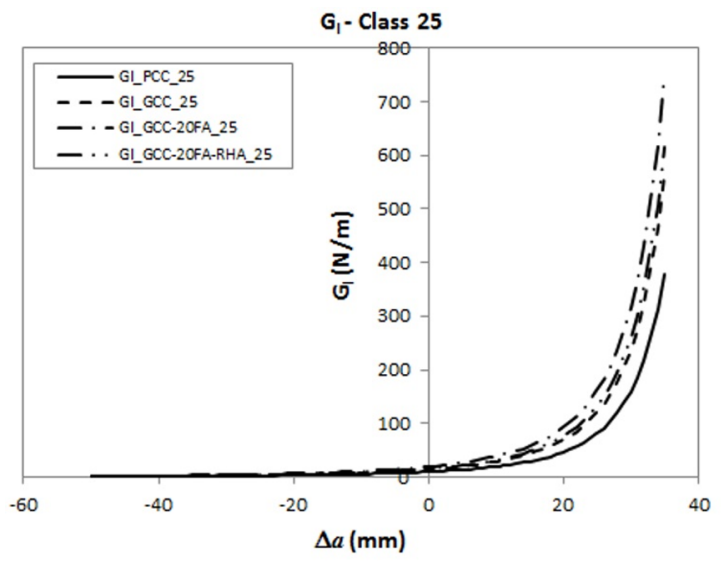

Figure 6. Variation of the rate of deformation energy release with the extension of the crack for concrete notched beams of strength class of $25 \mathrm{MPa}$ with different matrices.

Figure 7 shows the values of $\mathrm{G}_{\mathrm{I}}$ as a function of $\Delta a$ for the notched beams of class $40 \mathrm{MPa}$ and of different matrices.

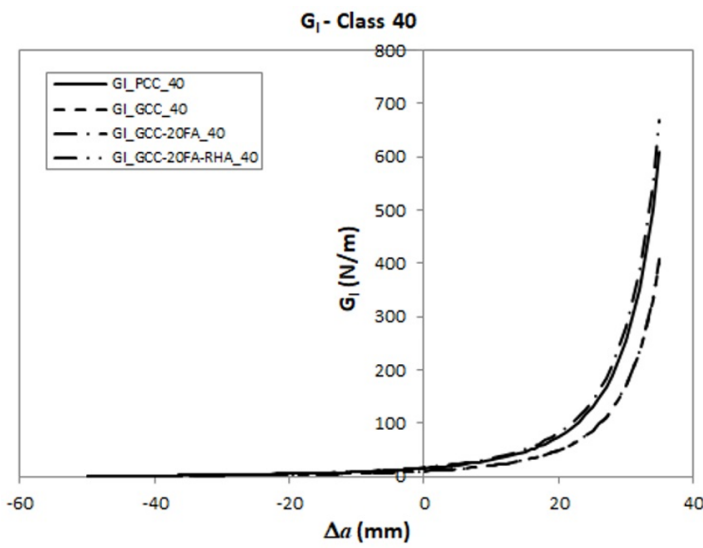

Figure 7. Variation of deformation energy release rate with the extension of the crack for concrete notched beams of strength class of $40 \mathrm{MPa}$ with, different matrices.

$\mathrm{G}_{\mathrm{I}}$ curves overlapped for GCC_40 and GCC-20FARHA_40 and for PCC_40 and GCC-20FA_40. These results were unexpected since the geopolymers had shown superior or equivalent behavior to PCC_40 in several other parameters as shown above, including $\mathrm{K}_{\mathrm{I}}$.
Since $\mathrm{G}_{\mathrm{I}}$ is directly proportional to $\left(\mathrm{K}_{\mathrm{I}}\right)^{2}$ and inversely proportional to the modulus of elasticity, then, for a same value of $\mathrm{K}_{\mathrm{I}}$, the smaller the value of $\mathrm{G}_{\mathrm{I}}{ }^{11}$.

Figure 8 presents the results of fracture resistance for concrete of class $25 \mathrm{MPa}$ in the different matrices studied. All the geopolymer small beams presented the plateau of the $\mathrm{R}_{\mathrm{I}}$-curve above the plateau of PCC_25, revealing its superiority in this parameter indicative of the toughness. Among the geopolymer beams, however, the best performance related to resistance to crack propagation was for GCC_25, with values $20 \%$ higher than for the GCC-20FA_25 and 50\% higher than the GCC-20FA-RHA_25. This corroborates with results obtained in the $\mathrm{K}_{\mathrm{I}}$ analysis.

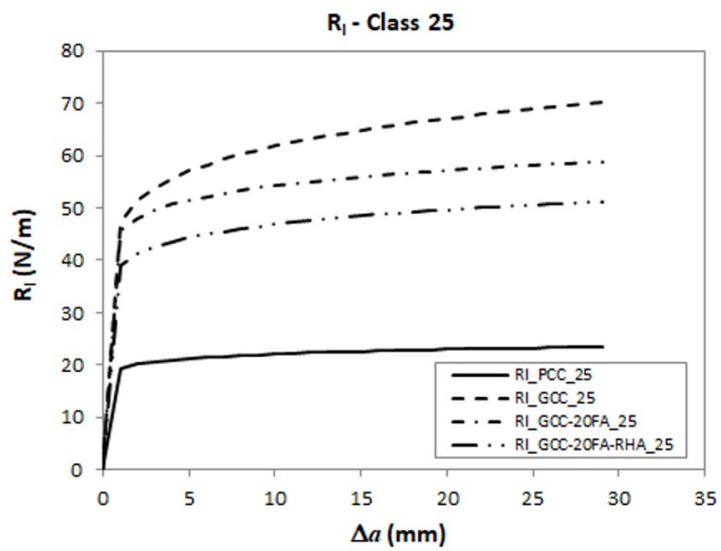

Figure 8. Variation of the $R_{I}$ curves with the extension of the crack for concrete notched beams of strength class of $25 \mathrm{MPa}$, with different matrices.

The results obtained for class $40 \mathrm{MPa}$ were lower than expected. The $\mathrm{R}_{\mathrm{I}}$-curve plateau for GCC_40 has fallen to half the value for GCC_25 (Figure 9).

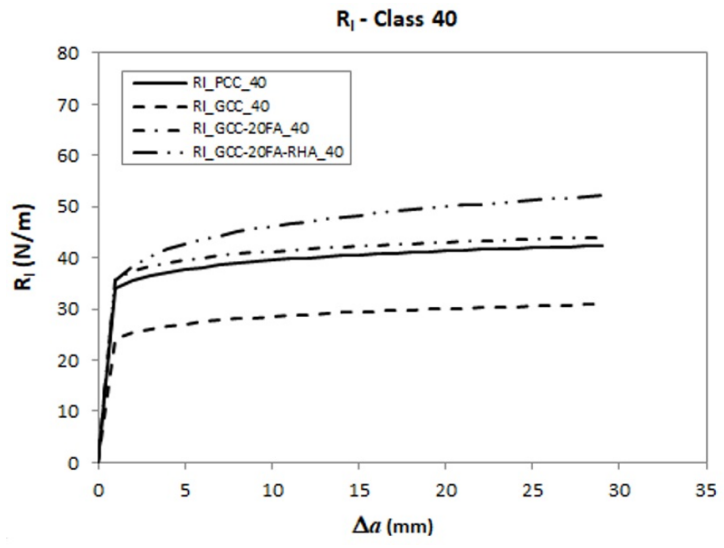

Figure 9. Variation of the $\mathrm{R}_{\mathrm{I}}$ curves with the extension of the crack for notched beams of concrete strength class of $40 \mathrm{MPa}$, with different matrices. 
The presence of fly ash and rice husk in the geopolymer did not have a significant influence on the performance of the different strength concrete classes. Whereas the GCC-20FA lost $20 \%$ of the resistance to the fracture with the increase of the strength class of the concrete.

Figures 10 and 11 show the average $\mathrm{P}-\delta$ curves obtained for each type of concrete studied, by classes 25 and 40 , respectively.

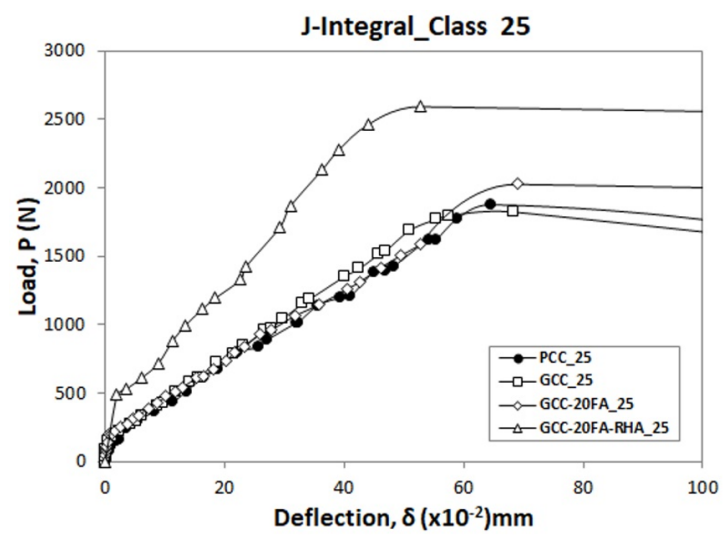

Figure 10. Average values of load-deflection curves in the middle of the span of the class 25 notched beams of different matrices.

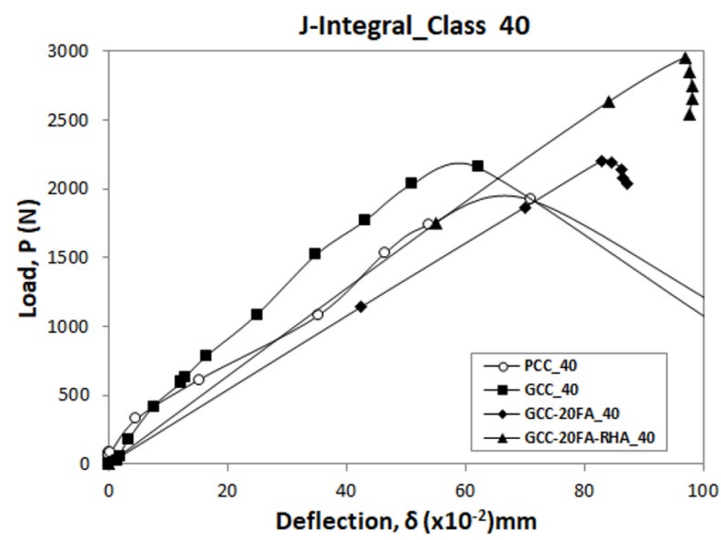

Figure 11. Average values of load-deflection curves in the middle of the span of the class 40 notched beams of different matrices.

Except for PCC notched beams, all the others presented increase of $\mathrm{P}_{\max }$ with the increase of strength class, especially the GCC-20FA-RHA.

The GCC showed increased stiffness with increased strength class, as expected. However, the other geopolymeric matrices, as well as the PCC, countered this expectation.

Table 2 compares the average values of the critical values of the fracture parameters for the notched beams of the different matrices and strength classes. For the $25 \mathrm{MPa}$ strength class, all geopolymers beams had fracture properties better than PCC_25.
Table 2. Average values of fracture parameters.

\begin{tabular}{lcccc}
\hline $\begin{array}{l}\text { Notched } \\
\text { Beam }\end{array}$ & $\begin{array}{c}\mathrm{K}_{\mathrm{Ic}}(\mathrm{MPa} . \\
\left.\mathrm{mm}^{1 / 2}\right)\end{array}$ & $\mathrm{G}_{\mathrm{Ic}}(\mathrm{N} / \mathrm{m})$ & $\mathrm{R}_{\mathrm{Ic}}(\mathrm{N} / \mathrm{m})$ & $\begin{array}{c}\boldsymbol{J} \boldsymbol{m a ́} \boldsymbol{x}(\mathrm{J} / \\
\left.\mathrm{m}^{2}\right)\end{array}$ \\
\hline PCC_25 & $28.45 \pm$ & $22.37 \pm$ & $22.38 \pm$ & $329.76 \pm$ \\
& 5.10 & 6.59 & 6.59 & 55.59 \\
GCC_25 & $46.08 \pm$ & $68.12 \pm$ & $68.14 \pm$ & $443.14 \pm$ \\
& 14.82 & 23.31 & 23.32 & 151.09 \\
GCC- & $38.72 \pm$ & $56.03 \pm$ & $56.04 \pm$ & $576.37 \pm$ \\
20FA_25 & 3.96 & 11.41 & 11.41 & 147.01 \\
GCC- & $50.17 \pm$ & $44.60 \pm$ & $44.62 \pm$ & $543.90 \pm$ \\
20FA- & 5.98 & 4.55 & 4.55 & 135.32 \\
RHA_25 & & & & \\
& $37.01 \pm$ & $40.36 \pm$ & $40.37 \pm$ & $146.93 \pm$ \\
PCC_40 & 4.22 & 10.73 & 10.73 & 12.88 \\
& $38.60 \pm$ & $29.46 \pm$ & $29.47 \pm$ & $358.15 \pm$ \\
GCC_40 & 5.29 & 11.92 & 11.93 & 93.70 \\
GCC- & $38.50 \pm$ & $41.91 \pm$ & $41.93 \pm$ & $386.17 \pm$ \\
20FA_40 & 2.91 & 14.95 & 14.96 & 115.76 \\
GCC- & $61.18 \pm$ & $50.21 \pm$ & $50.23 \pm$ & $454.15 \pm$ \\
20FA- & 8.06 & 6.46 & 6.47 & 56.27 \\
RHA_40 & & & &
\end{tabular}

Observing the $\mathrm{K}_{\mathrm{Ic}}$ parameters, there was loss of toughness of the geopolymer class 25 with the substitution of metakaolin with FA, but there was an increase when the RHA silicate was used. In the notched beams of class 40 , the superiority of geopolymer relative to Portland concrete was observed. The fracture toughness, $\mathrm{K}_{\mathrm{Ic}}{ }^{\mathrm{s}}$, of GCC-20FA-RHA_40 was $65.3 \%, 58.5 \%$ and $58.9 \%$ higher than PCC_40, GCC_40 and GCC-20FA_40, respectively. The RHA silicate could simultaneously increase the load bearing capacity and deflection of the beams in both strength classes, showing its potential as an alkali-activator and source of amorphous silica.

\section{Conclusions}

The analysis of the fracture properties of the concrete notched beams allowed the verification that for the same class of compressive strength, the geopolymer cement concrete is tougher than the Portland equalivant. Replacing the metakaolin with $20 \%$ volume fly ash (GCC-20FA) and rice rusk ash based silicate (GCC-20FA-RHA) further improved the performance of the concrete. The fracture toughness of GCC-20FA and GCC-20FA-RHA were measured from parameters such as $\mathrm{K}_{\mathrm{I}}$, J-Integral and R-curves, and showed values $100 \%$ higher than the Portland cement concrete.

\section{Acknowledgment}

The authors thank the Structural and Construction Materials Laboratories of UFF / Niterói and CAPES for their financial support. 


\section{References}

1. Vargas AS, Dal Molin DCC, Vilela ACF, Silva FJ, Pavão B, Veit $\mathrm{H}$. The effects of $\mathrm{Na}_{2} \mathrm{O} / \mathrm{SiO}_{2}$ molar ratio, curing temperature and age on compressive strength, morphology and microstructure of alkali-activated fly ash-based geopolymers. Cement \& Concrete Composites. 2011;33(6):653-660.

2. Silva FJ, Barbosa VFF, Thaumaturgo C. Use of Environmental Scanning Microscopy (ESEM) for Study of Alkali-Activated Pulverized Fly Ash. In: Proceedings of $6^{\text {th }}$ Brazilian Conference on Microscopy of Materials; 1998 Oct 25-27; Águas de Lindóia, SP, Brazil. 1998. p. 133-136.

3. Barbosa VFF, MacKenzie KJD, Thaumaturgo C. Synthesis and characterization of materials based on inorganic polymers of alumina and sílica: sodium polysialate polymers. International Journal of Inorganic Materials. 2000;2(4):309-317.

4. Davidovits J. High-alkali cements for $21^{\text {st }}$ century concretes. In: Concrete Technology, Past, Present Aand Future, ACI SP114. Farmington Hills: American Concrete Institute; 1994. p. 383-398.

5. Xu H, Van Deventer JS. The geopolymerization of aluminosilicate minerals. International Journal of Mineral Processing. 2000;59(3):247-266.

6. Xu H, Van Deventer JS. Geopolymerisation of multiple minerals. Minerals Engineering. 2000;15(12):1131-1139.

7. Davidovits J. Geopolymer Chemistry and Applications. $3^{\text {rd }}$ ed. Saint-Quentin: Institut Géopolymère; 2011.

8. Duxson P, Fernández-Jiménez A, Provis JL, Lukey GC, Palomo A, van Deventer JSJ. Geopolymer technology: the current state of the art. Journal of Materials Science. 2007;42(9):2917-2933.

9. Bittencourt TN. Fraturamento do concreto estrutural: aspectos teóricos, computacionais e experimentais, e suas aplicações. [Free teaching thesis]. São Paulo: Universidade de São Paulo; 1999.
10. Hillerborg A, Modéer M, Petersson PE. Analysis of crack formation and crack growth in concrete by means of fracture mechanics and finite elements. Cement and Concrete Research. 1976;6(6):773-781.

11. Jenq Y, Shah SP. Two Parameter Fracture Model for Concrete. Journal of Engineering Mechanics. 1985;111(10):1227-1241.

12. Bazant ZP, Kazemi MT. Determination of fracture energy, process zone length and brittleness number from size effect, with application to rock and concrete. International Journal of Fracture. 1990;44(2):111-131.

13. RILEM Committee on Fracture Mechanics of Concrete - Test Methods; Shah SP. Determination of fracture parameters $\left(\mathrm{K}_{\mathrm{Ic}}{ }^{\mathrm{s}}\right.$ and $\mathrm{CTOD}_{\mathrm{c}}$ ) of plain concrete using three-point bend tests. Materials and Structures. 1990;23(6):457-460.

14. Shinde SS, Dhamejani CL. Literature Review on Fracture Toughness and Impact Toughness. International Journal of Innovations in Engineering Research and Technology. 2015;2(11)1-5.

15. Irwin GR. Analysis of stress and strains near the end of a crack traversing a plate. Journal of Applied Mechanics. 1957;24:361364.

16. Rice JR. A Path Independent Integral and the Approximate Analysis of Strain Concentration by Notches and Cracks. Journal of Applied Mechanics. 1968;35(2):375-386.

17. Janssen M, Zuidema J, Wanhill RJH. Fracture Mechanics. $2^{\text {nd }}$ ed. Delft: Delft University Press; 2002. 365 p.

18. Xu S, Reinhardt HW. Crack Extension Resistance and Fracture Properties of Quasi-Brittle Softening Materials like Concrete Based on The Complete Process of Fracture. International Journal of Fracture. 1998;92:71-99.

19. Ouyang C, Mobasher B, Shah SP. An R-curve approach for fracture of quasi-britlle materials. Cement and Concrete Research. 1990;37(4):901-913. 